Click

\title{
Magnetic susceptibility as a tool to study deformed calcite with variable impurity content
}

\section{Bjarne S. G. Almqvist}

Institute of Geophysics, ETH Zurich, Sonneggstrasse 5, CH-8092 Zurich, Srwitzerland

(bjarne.almqvist@mag.ig.erdw.ethz.ch)

Marco Herwegh

Institute of Geological Sciences, Universität Bern, Baltzerstrasse 1+3, CH-3012 Bern, Switzerland

Volkmar Schmidt

K-UTEC AG Salt Technologies, D-99706 Sondershausen, Germany

\section{Thomas Pettke}

Institute of Geological Sciences, Universität Bern, Baltzerstrasse 1+3, CH-3012 Bern, Switzerland

\author{
Ann M. Hirt \\ Institute of Geophysics, ETH Zurich, Sonneggstrasse 5, CH-8092 Zurich, Switzerland
}

[1] A set of calcite mylonites were systematically sampled along the basal shear zone of the Morcles Nappe, located in the southwestern Swiss Alps, to investigate the relationship among crystallographic preferred orientation (CPO), chemistry, and anisotropy of magnetic susceptibility (AMS). Second-phase minerals are $\leq 10 \mathrm{vol} \%$ of the rock. The substitution of trace impurities for Ca in the calcite crystal lattice, in particular, $\mathrm{Fe}, \mathrm{Mn}, \mathrm{Mg}$, and $\mathrm{Sr}$, varies among the samples with total values ranging from $1450 \pm 190 \mathrm{ppm}$ in the most pure sample to $2450 \pm 320 \mathrm{ppm}$ for the most impure sample. Fe shows the largest variation among the sample group and varies by a factor of nearly four from the purest $(230 \pm 30 \mathrm{ppm})$ to the most impure sample $(840 \pm 110 \mathrm{ppm})$. All samples have negative bulk susceptibility, and the concentration of ferromagnetic (in a broad sense) phases is very low. A correlation is identified between trace element chemistry, CPO of calcite, and the magnetic susceptibility. The bulk susceptibility and the AMS vary systematically with $\mathrm{Fe}$ and $\mathrm{Mn}$ elemental concentration in the matrix calcite, and this variation is apparent for the entire length of the shear zone. A simple model that takes into account the CPO and trace element chemistry is used to explain the resulting bulk susceptibility and AMS. Calcite mylonites and marbles from other locations fit the model, indicative of a general relationship between CPO, chemistry, and AMS in calcites where second-phase minerals are sparse. For lithologies that are dominated magnetically by calcite, with a deficiency of secondary phases, magnetic susceptibility can be used to rapidly screen rock samples for the variation of paramagnetic trace elements Fe and $\mathrm{Mn}$ and $\mathrm{CPO}$, which can then be used for detailed microfabric studies.

Components: 9269 words, 8 figures, 2 tables.

Keywords: magnetic susceptibility; anisotropy; CPO; calcite; chemical impurity.

Index Terms: 1518 Geomagnetism and Paleomagnetism: Magnetic fabrics and anisotropy; 8012 Structural Geology: High strain deformation zones.

Received 12 October 2009; Accepted 19 November 2009; Published 19 January 2010. 
Almqvist, B. S. G., M. Herwegh, V. Schmidt, T. Pettke, and A. M. Hirt (2010), Magnetic susceptibility as a tool to study deformed calcite with variable impurity content, Geochem. Geophys. Geosyst., 11, Q01Z09, doi:10.1029/2009GC002900.

Theme: Magnetism From Atomic to Planetary Scales: Physical Principles and Interdisciplinary Applications in Geoscience

Guest Editors: J. Feinberg, F. Florindo, B. Moskowitz, and A. P. Roberts

\section{Introduction}

[2] Strain observed in tectonic and orogenic settings tends to localize in shear zones, commonly in weak lithologies such as carbonates [Heitzmann, 1987; van der Pluijm, 1991; Kennedy and Logan, 1998; Kennedy and White, 2001; Bestmann et al., 2000; Ebert et al., 2007; Austin et al., 2008; Herwegh et al., 2008]. Several factors are important for the development of rock microfabrics, including strain, strain rate, stress, temperature, and the mode and mechanism of deformation. Another important factor that influences the deformation processes, as has been shown in carbonate rocks, is the secondphase content [Olgaard and Evans, 1986, 1988; Herwegh et al., 2005; Ebert et al., 2007; Herwegh and Berger, 2004] and the presence and amount of chemical impurities [e.g., Freund et al., 2001, 2004; Herwegh et al., 2003; Xu et al., 2009]. Chemical impurities are defined here as cations that substitute for the calcium $\left(\mathrm{Ca}^{2+}\right)$ cation in the carbonate crystal lattice (i.e., iron-substituted calcite), whereas second phases refer to mineral species other than calcite, following common convention in the rock deformation community [e.g., Olgaard and Evans, 1986; Herwegh and Kunze, 2002]. Bulk magnetic susceptibility and anisotropy of magnetic susceptibility (AMS) are direct results of these factors, similar to the development of the crystallographic preferred orientation (CPO).

[3] The AMS is a product of the juxtaposition of individual minerals' crystallographic preferred orientation and shape preferred orientation (SPO) in a rock and therefore is a commonly applied petrophysical tool used to infer the petrofabric of a rock. Although AMS has long been recognized as successful in detecting petrofabrics [cf. Ising, 1942; Graham, 1954, 1966; Kligfield et al., 1977; Hrouda, 1982; Borradaile and Henry, 1997], new questions and problems have arisen as the development of the method has progressed. Examples include the cause of inverse magnetic fabrics, e.g., from single-domain magnetite, or some paramagnetic minerals [Potter and Stephenson, 1988;
Rochette et al., 1992], or the frequency and field dependence of ferromagnetic mineralogies [Jackson et al., 1998; de Wall and Worm, 1993; Hrouda, 2002]. The measured AMS is the sum of contributions from all mineral phases within the sample volume and the challenge becomes to determine their respective quantitative contributions to the overall magnetic fabric [e.g., Rochette et al., 1992]. Obtaining the quantitative contribution of a specific mineral is of interest, for example, when relating AMS to the petrofabric or texture strength (CPO). Several AMS techniques attempt the separation of individual mineral contributions [cf. Martín-Hernández and Ferré, 2007]. In addition the use of the anisotropy of remanent magnetization can be used to determine the anisotropy due to ferromagnetic minerals [McCabe et al., 1985; Jackson and Tauxe, 1991]. When several mineral species are present in a rock, the resulting AMS commonly produces intermediate magnetic fabrics or mix of magnetic anisotropies, leading to a complex relationship between petrofabric and AMS [Rochette, 1987; Potter and Stephenson, 1988; Rochette et al., 1999; Ferré, 2002].

[4] The magnitude or degree of AMS can be expressed as the ratio or difference between the axes of maximum and minimum susceptibility [e.g., Nagata, 1961; Owens, 1974]. A pure single crystal of calcite is diamagnetic and has a susceptibility of $-12.82 \times 10^{-6} \mathrm{SI}\left(-4.73 \times 10^{-9} \mathrm{~m}^{3} / \mathrm{kg}\right)$ parallel to its crystallographic $c$ axis and $-11.71 \times 10^{-6} \mathrm{SI}$ $\left(-4.32 \times 10^{-9} \mathrm{~m}^{3} / \mathrm{kg}\right)$ in the plane of the crystal $a$ axes [Schmidt et al., 2006]; the average bulk susceptibility of calcite is $-12.09 \times 10^{-6} \mathrm{SI}(-4.46 \times$ $10^{-9} \mathrm{~m}^{3} / \mathrm{kg}$ ). Hence, in an aggregate of pure calcite crystals, the AMS corresponds to the strength of the CPO [e.g., Owens and Rutter, 1978; de Wall et al., 2000; Schmidt et al., 2009]. The AMS of a bulk diamagnetic sample is, however, strongly influenced by impurities and second-phase minerals. These occur as solid solutions of paramagnetic cations in the crystal lattice or as minor amounts of paramagnetic and ferromagnetic (in a broad sense) phases. The effect of iron and manganese has been observed 


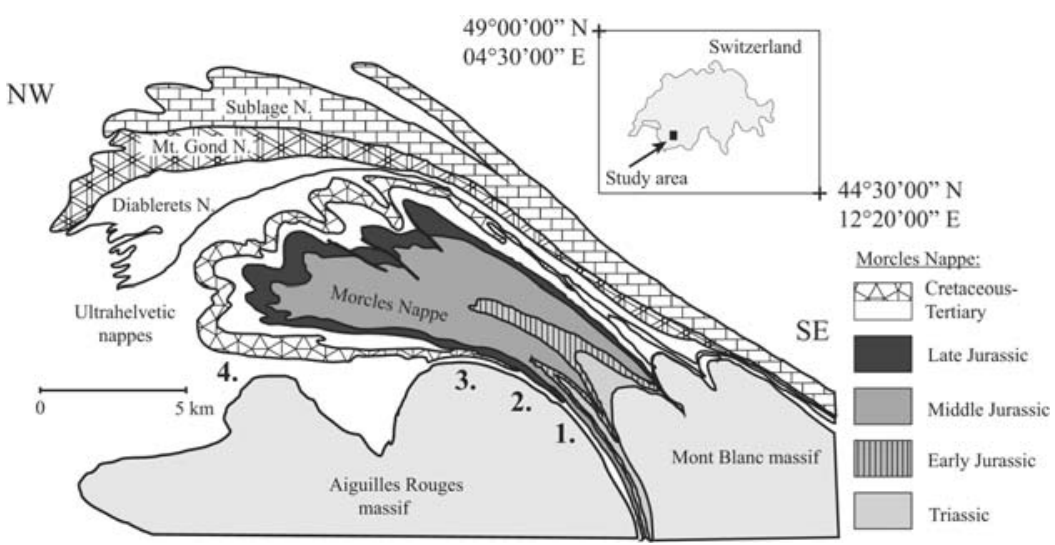

Figure 1. Cross-section map showing four of the five sampling locations along the shear zone, together with an inset map with the location of the Morcles Nappe. The numbers represent the sampling locations: 1, LQ; 2, UQ; 3 , LC; 4, Dent. The sampling location referred to as Martigny in Figure 2 represents the root zone of the nappe. It was displaced after faulting along the Rhône-Simplon line [see Ebert et al., 2007, Figure 1]. Modified after Escher et al. [1993], copyright 1993, and Ebert et al. [2007] copyright 2007, both with permission from Elsevier.

in single crystals and natural rocks where calcite constitutes the matrix mineral and the amount of other second phases is small [Rochette, 1988; Ihmlé et al., 1989; Schmidt et al., 2006, 2007a, 2007b; Almqvist et al., 2009].

[5] This study aims to illustrate the importance of chemical composition and crystallographic preferred orientation for describing the resulting AMS in carbonate-rich rocks. The magnetic susceptibility and its anisotropy, in return, provide a sensitive proxy for paramagnetic trace elements ( $\mathrm{Fe}$ and $\mathrm{Mn}$ ) and the CPO. The relationship between AMS, texture measurements and chemical composition is explored for a series of calcite mylonite samples from the basal shear zone of the Morcles Nappe located in southwestern Switzerland [Ramsay, 1981; Durney, 1972; Dietrich and Song, 1984; Ebert et al., 2007; Austin et al., 2008]. The role of chemical impurities on rheological properties in calcite rocks is addressed.

\section{Samples and Methods}

\subsection{Samples}

[6] A set of samples were taken from white and light gray calcite mylonites, which in the literature are referred to as white and gray Urgonian, of Aptian-Albian age [Stampfli et al., 2001; Föllmi and Gainon, 2008], at five locations along the basal thrust of the Morcles Nappe in southwestern Switzerland (Figure 1). These calcites have experienced lower greenschist facies metamorphism, during which they achieved steady state dynamic recrystallization, with shear strain $(\gamma)$ greater than
17 [Durney, 1972; Frey et al., 1980; Dietrich, 1989; Ebert et al., 2007]. Shear strain is defined as $\gamma=\tan \Psi$, where $\Psi$ is the angle of rotation for a line that is oriented normal (vertical) to the horizontal plane prior to deformation, and the orientation of the same line subsequent to shear deformation [Hatcher, 1995]. The gray color results from small amounts of nanosized organic matter [Herwegh and Kunze, 2002]. Secondary phase minerals make up $<10$ vol $\%$ of the sample's total volume, and include phyllosilicates, quartz, dolomite and chlorite [Ebert et al., 2007]. The intensity of deformation, as inferred from the CPO strength and microstructures, varies considerably across [Austin et al., 2008], and along [Ebert et al., 2007] the shear zone. Core specimens with a diameter of $25.4 \mathrm{~mm}$ and $22 \mathrm{~mm}$ height were drilled from block samples in the laboratory using a diamond drill bit.

\subsection{Anisotropy of Magnetic Susceptibility}

[7] The low-field (LF) magnetic anisotropy was determined with the Agico KLY-4 and KLY-3 Kappabridges, using a $300 \mathrm{~A} / \mathrm{m}$ alternating field with $875 \mathrm{~Hz}$ measurement frequency. All bulk susceptibility measurements were performed at room temperature. High-field (HF) measurements were carried out with a torsion magnetometer, which determines the deviatoric AMS [Bergmüller et al., 1994]. HF measurements were performed at room temperature and at $77 \mathrm{~K}$ [cf. Schmidt et al., 2007a]. Magnetic susceptibility (k) is a physical rock property, which is mathematically described by a second rank tensor, and whose eigenvalues can be used to represent the principal axes of a 
susceptibility ellipsoid, defined by $\mathrm{k}_{1} \geq \mathrm{k}_{2} \geq \mathrm{k}_{3}$. The parameter used to describe the degree of anisotropy is given by $\Delta \mathrm{k}=\mathrm{k}_{1}-\mathrm{k}_{3}$, where $\mathrm{k}_{1}$ and $\mathrm{k}_{3}$ are the maximum and minimum magnetic susceptibilities, respectively. Technically, high-field measurements determine the deviatoric susceptibility, which describes the deviation of the susceptibility ellipsoid from a sphere [Stacey, 1960]. It is therefore not possible to use the conventional $\mathrm{P}$ or Pj [Nagata, 1961; Jelinek, 1981] parameters to describe the degree of anisotropy for high-field measurements. However, $\Delta \mathrm{k}$ is still valid in this case, since it is not dependent on the size of the magnetic susceptibility, but rather on the deviation from the average susceptibility [e.g., Owens, 1974; Owens and Rutter, 1978; Schmidt et al., 2006]. We define the principal susceptibility axes of calcite, being diamagnetic, with $\mathrm{k}_{1}$ having the least negative value (smallest absolute value) and $\mathrm{k}_{3}$ having the most negative value (largest absolute value [Hrouda, 2004; Schmidt et al., 2006]). This leads to a calcite single-crystal AMS with rotational oblate shape ellipsoid.

\subsection{Texture Measurements}

[8] Texture measurements were made using a Zeiss Evo 50XVP scanning electron microscope (SEM) equipped with a Digi View II electron backscatter diffraction (EBSD) camera and the OIM data acquisition software (Ametek, TSL). Working conditions for the SEM were set to a $20 \mathrm{kV}$ acceleration voltage and a beam current of $10 \mathrm{nA}$, with varying working distances ranging from $9.0 \mathrm{~mm}$ to $19.5 \mathrm{~mm}$ and the sample stage tilted by $70^{\circ}$. The acquisition of EBSD patterns under low vacuum conditions $(10 \mathrm{~Pa})$ allowed the use of noncoated and therefore nonconducting sample surfaces. The acquisition of EBSD patterns is automated, with a $15 \mu \mathrm{m}$ step size over a $1600 \times 1600 \mu \mathrm{m}$ sample area. The collected data were processed with the OIM 5.3 orientation imaging microscopy software package from Ametek/TSL. Only data points measured with a confidence index $\geq 0.1$ were used for further data analysis. Calcite texture pole figures were plotted with the PF_PC software (i.e., Figure 4) (D. Mainprice, personal communication, 2009). Texture strength is given by the J index [e.g., Bunge, 1982] and the $\mathrm{M}$ index [Skemer et al., 2005]. The J index is based on a spherical harmonics series expansion of the orientation distribution function (ODF), and ranges from unity, representing a random fabric, to infinity, which represents the fabric of a single crystal. The M index is defined by the difference of uncorrelated misorientation angles of grains in the measured sample, to the uncorrelated misorientation angles of a theoretical random distribution of the same mineral. The larger the difference is between the two sets of misorientation angles, the stronger is the texture. The $\mathrm{M}$ index varies from zero, in the case of a random fabric, to one in the case of a single crystal fabric.

\subsection{Chemical Composition}

[9] Element concentration measurements were performed on selected samples using laser ablation inductively coupled plasma mass spectrometry (LA-ICP-MS), at the Institute of Geological Sciences, University of Bern, Switzerland. A Geolas $193 \mathrm{~nm}$ ArF excimer laser system was used for the ablation, in combination with an ELAN DRC-e quadrupole ICP-MS, run at conditions similar to those reported by Pettke [2008]. Samples were prepared as petrographic thin sections, with thicknesses around $100 \mu \mathrm{m}$, so as to allow sufficient time for the laser to ablate material during measurements lasting up to $60 \mathrm{~s}$; laser spot diameter sizes ranged from $24 \mu \mathrm{m}$ to $44 \mu \mathrm{m}$. External calibration was done using NIST SRM612 measurements bracketing up to 16 unknowns, allowing for drift correction and the quantification of element concentrations was done by internal standardization to the abundance of $\mathrm{Ca}$. Data reduction was performed with Lamtrace [Jackson, 2008].

\section{Results}

\subsection{Anisotropy of Magnetic Susceptibility}

[10] Figure 2a shows the LF-AMS for the set of calcite mylonites. All specimens have diamagnetic bulk susceptibilities, ranging from $-12.96 \times 10^{-6}$ to $-0.76 \times 10^{-6} \mathrm{SI}$. The values of $\Delta \mathrm{k}$ vary from $0.41 \times 10^{-7}$ to $8.03 \times 10^{-7}$ SI and the plot of $\Delta \mathrm{k}$ against bulk susceptibility is $\mathrm{V}$-shaped, with $\Delta \mathrm{k}$ having the lowest values for bulk susceptibilities between $-6.78 \times 10^{-6}$ and $-9.49 \times 10^{-6}$ SI. The deviatoric susceptibility, measured in high fields at room temperature, is shown in Figure $2 b$ as a function of bulk susceptibility. A V shape is also evident in the high-field data, with low $\Delta \mathrm{k}$ values in a similar range of bulk susceptibility as for the low-field data. A subtle feature displayed by both the LF and HF AMS data (Figures $2 a$ and $2 b$ ) is that $\Delta \mathrm{k}$ has two points of minimum values along the axis of bulk susceptibility; one minimum is found around -9.5 to $-9.8 \times 10^{-6} \mathrm{SI}$, whereas a second minimum is displaced slightly to the right, 

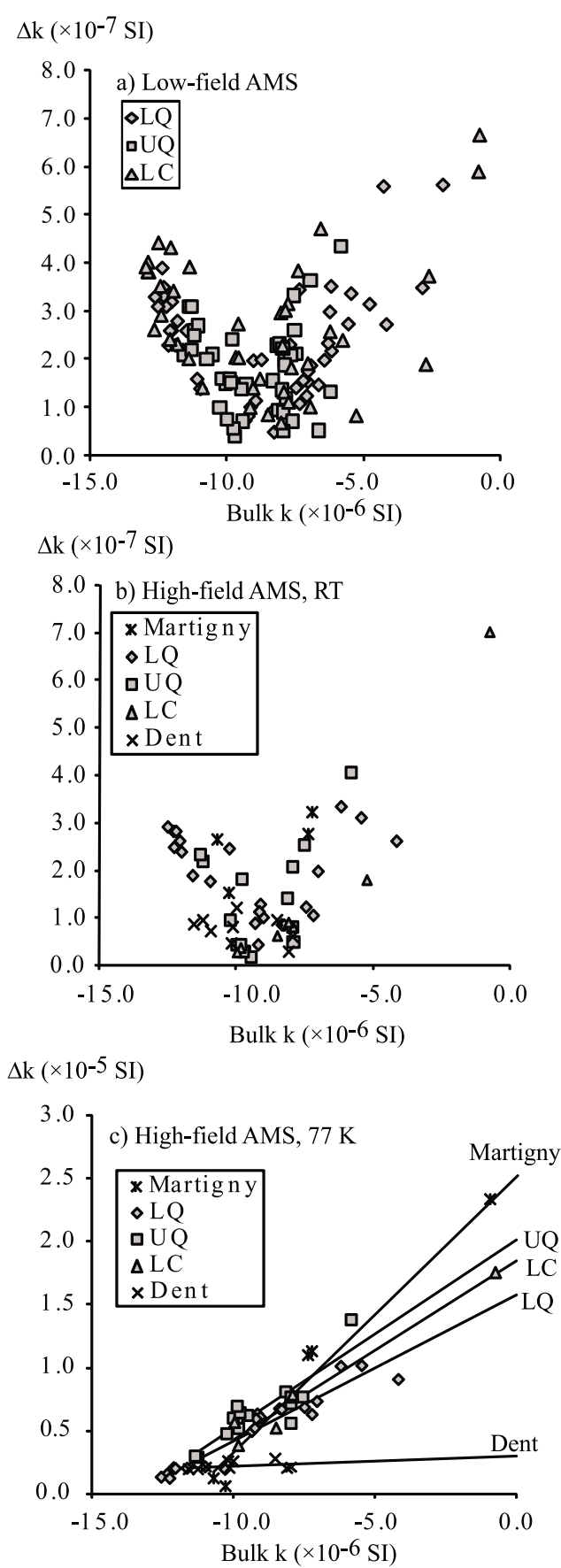

Figure 2. The susceptibility difference $(\Delta \mathrm{k})$ plotted as a function of bulk susceptibility for (a) LF-AMS, (b) HF-AMS at room temperature, and (c) HF-AMS at $77 \mathrm{~K}$. The legends indicate from which location along the shear zone the specimens originate.

at $-8.1 \times 10^{-6}$ SI. The $\Delta \mathrm{k}$ values measured at $77 \mathrm{~K}$ display a linear trend when plotted against the room temperature bulk susceptibility (Figure 2c), with $\Delta \mathrm{k}$ increasing as the bulk susceptibility approaches zero. The orientation of the principal susceptibility axes are shown in Figure 3, for room temperature (HF and LF) and $77 \mathrm{~K}$ measurements. At room temperature the principal axes varies with respect to the foliation plane (being horizontal in Figure 3 ), and the maximum and minimum susceptibility are oriented either normal to the foliation or in the foliation plane depending on the sample. At $77 \mathrm{~K}$ all samples have a similar distribution of the principal axes, with $\mathrm{k}_{1}$ is oriented normal to the foliation and $\mathrm{k}_{3}$ in the plane of the foliation, in agreement with iron-rich calcite dominating the AMS at $77 \mathrm{~K}$. The complete database that is used in the current study (the data in Figure 2) is presented in tabulated form and attached as auxiliary material. ${ }^{1}$

\subsection{Texture Analysis}

[11] Five specimens of gray Urgonian were selected for texture measurements with EBSD, based on their variation in bulk susceptibility and $\Delta \mathrm{k}$ (Figure 4a). Each of these specimens was drilled from a different hand sample, but they were collected within $10 \mathrm{~m}$ of one another and from the same lithological layer in the same outcrop. A summary of the texture data from EBSD analysis is presented in Table 1. The (001) pole figures display a $c$ axis concentration normal to the foliation plane (Figures $4 b-4 f$ ) for all specimens whereas $a$ axes (not plotted) show a girdled distribution within the plane of foliation. The J, M, and MUDc indices are consistent with one another for each of the five investigated specimens, with highest CPO strength for specimen UQ0801, and lowest CPO strength for UQ0202B.

\subsection{Chemical Composition}

[12] Four of the five specimens used for texture analysis (UQ0101A, UQ0801, UQ1001, and UQ1102C) were analyzed for their elemental composition with LA-ICP-MS. The complete results of the measurements are provided in Table 2, and the $\mathrm{Fe}$ and $\mathrm{Mn}$ results are also summarized in Table 1. Thin sections used for laser ablation were prepared from the same specimen as those used for texture analysis. The thin sections were dominantly made up of fine-grained recrystallized calcite matrix, with dispersed fragments of fossils (Echinodermata phylum) which have resisted recrystallization during deformation. The chemical composition of individual grains of the matrix calcite was possible to analyze (Tables 1 and 2), but since the calcite

${ }^{1}$ Auxiliary materials are available at $\mathrm{ftp} / / \mathrm{ftp}$.agu.org/apend/gc/ $2009 \mathrm{gc002900}$. 

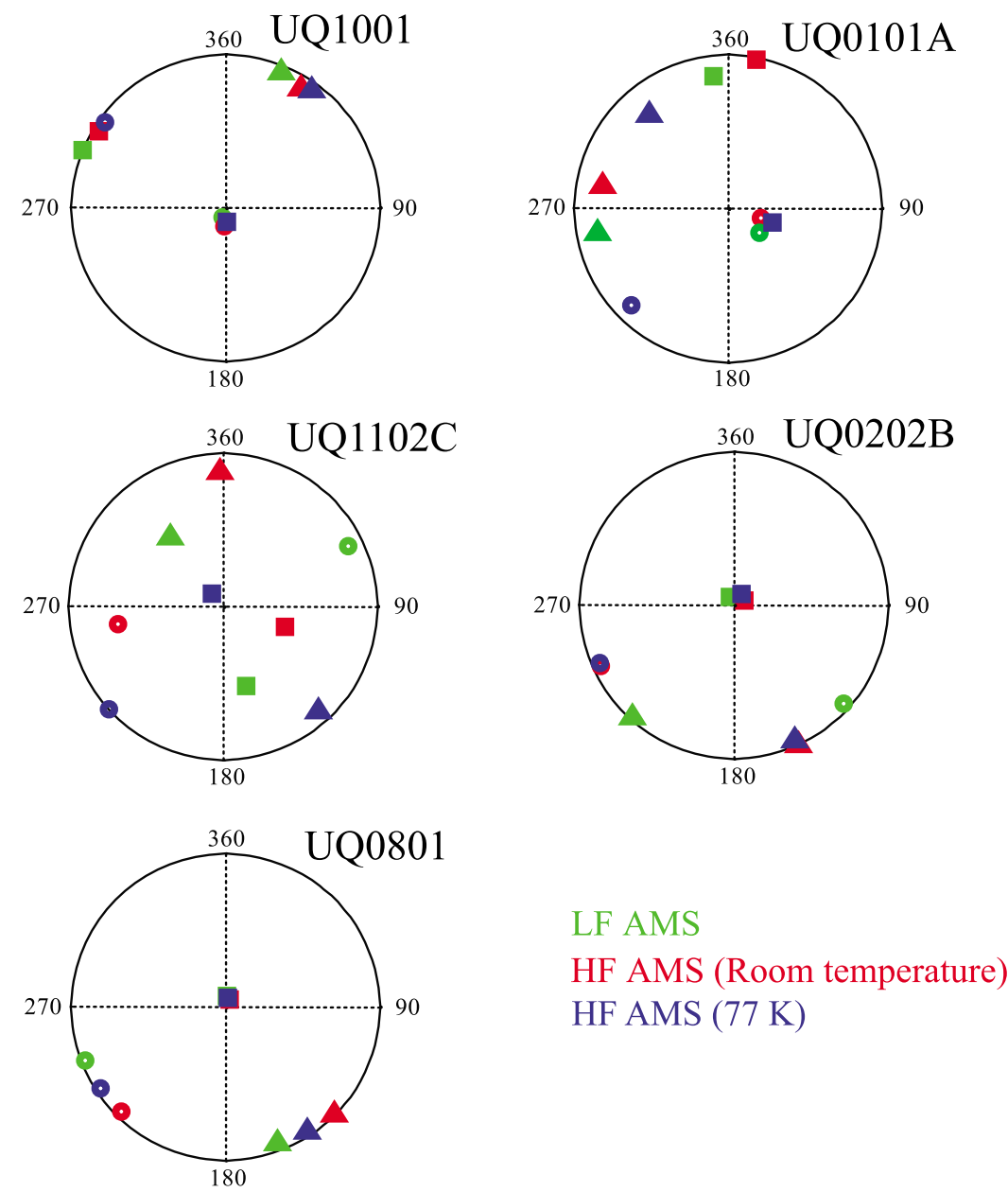

HF AMS (Room
HF AMS $(77 \mathrm{~K})$

Figure 3. Equal area projections with axes of maximum (squares), intermediate (triangles), and minimum (circles) susceptibility for five specimens that were selected for EBSD texture measurements. The edge of the stereonet represents the plane of specimen foliation, and the center of the stereonet is the normal to the foliation plane. Principal axes are shown for LF-AMS (green symbols), room temperature HF-AMS (red symbols), and HF-AMS at 77 K (blue symbols).

grains are small the analysis commonly extended across grain boundaries. This sometimes led to the signal being influenced by small second phases, not visible under the microscope, located at the calcite grain boundaries. Second-phase minerals were checked for aluminum by careful signal inspection, and the part of the signal containing elevated aluminum was removed from any further data analysis. In each thin section selected fossils were also targeted and measured with the LA-ICP-MS (Table 2 and Figure 5).

[13] The recrystallized calcite matrix displays a variation in the concentration of $\mathrm{Fe}$ and $\mathrm{Mn}$, being lowest in specimen UQ1001 (230 ppm Fe; 23 ppm $\mathrm{Mn}$ ) and highest for specimen UQ0801 (840 ppm $\mathrm{Fe}$; $48 \mathrm{ppm} \mathrm{Mn}$ ). In general, the Fe concentration of the matrix is about 10-20 times larger than the $\mathrm{Mn}$ concentration. $\mathrm{Mg}$ and $\mathrm{Sr}$ also display system- atic variations in accordance with the variations of $\mathrm{Fe}$ and $\mathrm{Mn}$ between the different specimens (Table 2). In contrast, the amount of $\mathrm{Fe}$ and $\mathrm{Mn}$ in the echinoderms is more consistent between specimens (160-240 ppm Fe; 23-45 ppm Mn), but again with a greater amount of Fe compared to $\mathrm{Mn}$. The $\mathrm{Mg}$ concentration is similar for the matrix and echinoderm fragments, and it is difficult to make a distinction between them based on the $\mathrm{Mg}$. The $\mathrm{Sr}$ concentration is consistently higher in the echinoderm fragments, compared to the calcite matrix. Other elements are present in sub ppm concentrations and show slight enrichment in the echinoderms compared to the matrix. Specimen UQ0801 has consistently the highest impurity content and also the largest number of echinoderm fragments (identified from counting in thin section), whereas specimen UQ1001 shows the least 
a) $\Delta \mathrm{k}\left(\times 10^{-7} \mathrm{SI}\right)$

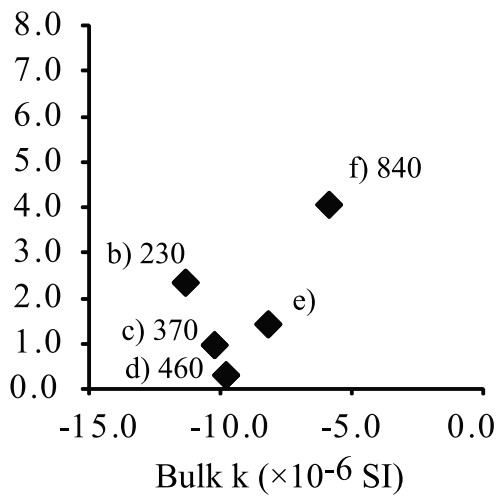

b) UQ1001 Z

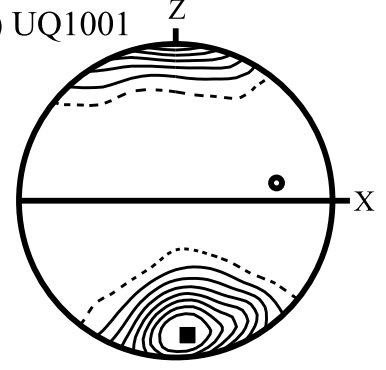

c) UQ0101A Z

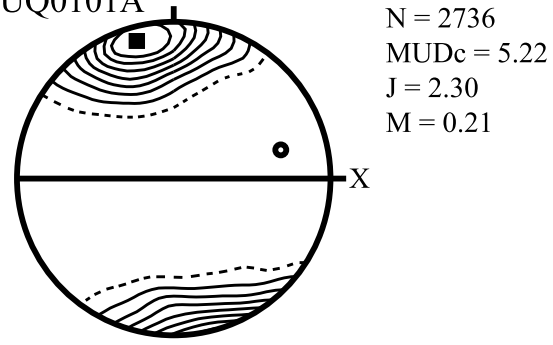

$\mathrm{N}=2895$

MUDc $=5.40$

$\mathrm{J}=2.21$

$\mathrm{M}=0.20$ d)

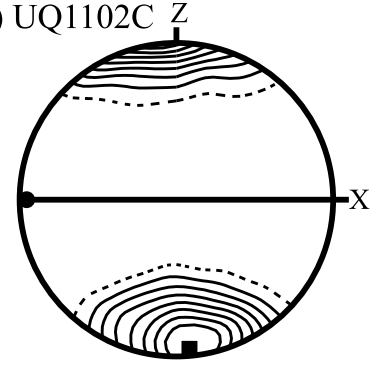

$\mathrm{N}=2531$

MUDc $=5.36$

$\mathrm{J}=2.29$

$\mathrm{M}=0.20$

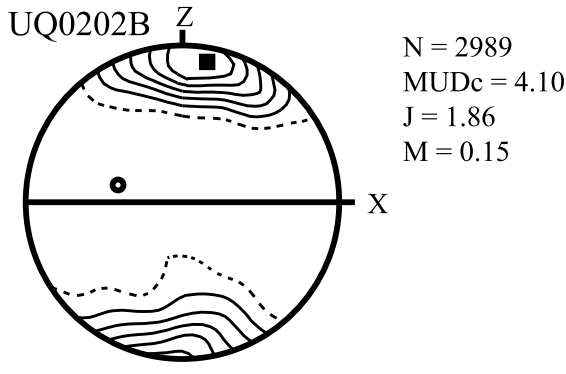

e)

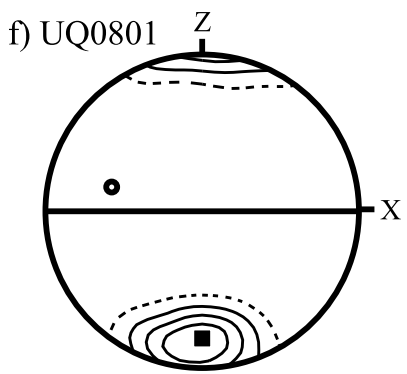

$\mathrm{N}=2974$

MUDc $=6.17$

$\mathrm{J}=2.78$

$\mathrm{M}=0.29$

Figure 4. (a) The susceptibility difference $(\Delta \mathrm{k})$ as a function of bulk susceptibility for five specimens that were selected for EBSD texture measurements. The number next to each letter indicates the amount of $\mathrm{Fe}$ in ppm, obtained from LA-ICP-MS. ( $b-f)$ Texture results for five specimens from the gray Urgonian, collected from the Upper Quarry location in the shear zone. In Figures $4 \mathrm{~b}-4 \mathrm{f}$ the $z$ axis represents the normal to the foliation plane, and the $x$ axis represents the axis of mineral lineation; the square (circle) represents the maximum (minimum) clustering of crystal $c$ axes. The data are smoothed with a Gaussian fit of $8.5^{\circ}$ half-width and presented in equal area, lower hemisphere projections with contours of multiples of uniform distributions (MUDc) for the crystal $c$ axis; each contour represent $0.5 \mathrm{MUDc}$, except for specimen UQ0801 where each contour represents 1.0 MUDc. $\mathrm{N}$ is the number of discrete Euler angle data points used for the pole figure plot, $J$ is the $J$ index [e.g., Bunge, 1982], and $M$ is the $M$ index [Skemer et al., 2005].

Table 1. Summary of Magnetic Susceptibility and Texture Results for Five Selected Gray Urgonian Specimens

\begin{tabular}{|c|c|c|c|c|c|c|c|c|c|c|c|c|}
\hline \multirow[b]{2}{*}{ Specimen } & \multirow[b]{2}{*}{$\mathbf{k}(\mathrm{SI})$} & \multirow[b]{2}{*}{$\begin{array}{c}\Delta \mathrm{k}^{\mathrm{HF}} \\
(\mathrm{SI})\end{array}$} & \multirow[b]{2}{*}{$\begin{array}{c}\Delta \mathrm{k}^{\mathrm{LF}} \\
(\mathrm{SI})\end{array}$} & \multirow[b]{2}{*}{$\mathrm{U}^{\mathrm{HFa}}$} & \multirow[b]{2}{*}{$\mathrm{U}^{\mathrm{LFa}}$} & \multirow[b]{2}{*}{$\begin{array}{c}\mathrm{J} \\
\text { Index }\end{array}$} & \multirow[b]{2}{*}{$\begin{array}{c}\mathrm{M} \\
\text { Index }\end{array}$} & \multirow[b]{2}{*}{ MUDc $^{\mathrm{b}}$} & \multicolumn{2}{|c|}{ Matrix } & \multicolumn{2}{|c|}{ Echinoderm } \\
\hline & & & & & & & & & $\begin{array}{c}\mathrm{Fe} \\
(\mathrm{ppm})\end{array}$ & $\begin{array}{c}\mathrm{Mn} \\
(\mathrm{ppm})\end{array}$ & $\begin{array}{c}\mathrm{Fe} \\
(\mathrm{ppm})\end{array}$ & $\begin{array}{c}\mathrm{Mn} \\
(\mathrm{ppm})\end{array}$ \\
\hline UQ0101A & $-1.02 \mathrm{E}-05$ & $9.46 \mathrm{E}-08$ & $1.60 \mathrm{E}-07$ & 0.56 & 0.19 & 2.3 & 0.21 & 5.22 & $370 \pm 100$ & $31 \pm 3$ & $220 \pm 60$ & $28 \pm 5$ \\
\hline UQ0202B & $-8.16 \mathrm{E}-06$ & $1.41 \mathrm{E}-07$ & $2.29 \mathrm{E}-07$ & -0.72 & -0.47 & 1.86 & 0.15 & 4.1 & & & & \\
\hline UQ0801 & $-5.83 \mathrm{E}-06$ & 4.04E-07 & 4.34E-07 & -0.94 & -0.73 & 2.78 & 0.29 & 6.17 & $840 \pm 110$ & $48 \pm 6$ & $240 \pm 190$ & $47 \pm 13$ \\
\hline UQ1001 & $-1.13 \mathrm{E}-05$ & 2.33E-07 & $2.20 \mathrm{E}-07$ & 0.66 & 0.87 & 2.21 & 0.20 & 5.4 & $230 \pm 30$ & $23 \pm 1$ & $160 \pm 20$ & $23 \pm 13$ \\
\hline UQ1102C & $-9.76 \mathrm{E}-06$ & 2.82E-08 & $5.60 \mathrm{E}-08$ & 0.12 & 0.51 & 2.29 & 0.20 & 5.36 & $460 \pm 60$ & $28 \pm 2$ & $200 \pm 80$ & $24 \pm 15$ \\
\hline
\end{tabular}

${ }^{\mathrm{a}} \mathrm{U}=\left(2 * \mathrm{k}_{2}-\mathrm{k}_{1}-\mathrm{k}_{3}\right) /\left(\mathrm{k}_{1}-\mathrm{k}_{3}\right)$.

${ }^{\mathrm{b}}$ Multiples of uniform distribution of the crystal $c$ axis. 
Geochemistry

Table 2. Summary of Elemental Concentrations of the Calcite Matrix and Echinoderm Fragment ${ }^{\mathrm{a}}$

\begin{tabular}{|c|c|c|c|c|c|c|c|c|c|c|c|}
\hline Specimen & $\mathrm{n}^{\mathrm{b}}$ & $\mathrm{Fe}$ & $\mathrm{Mn}$ & $\mathrm{Mg}$ & $\mathrm{Sr}$ & $\mathrm{Al}$ & $\mathrm{Ba}$ & $\mathrm{La}$ & $\mathrm{Ce}$ & $\mathrm{Nd}$ & $\mathrm{Pb}$ \\
\hline \multicolumn{12}{|c|}{ Matrix } \\
\hline UQ1001 & 6 & $230 \pm 30$ & $23 \pm 1$ & $1100 \pm 130$ & $100 \pm 30$ & $0.9 \pm 0.6$ & $0.5 \pm 0.3$ & $0.3 \pm 0.2$ & $0.4 \pm 0.3$ & $0.2 \pm 0.1$ & $0.5 \pm 0.3$ \\
\hline UQ0101A & 9 & $370 \pm 100$ & $31 \pm 3$ & $1210 \pm 170$ & $130 \pm 10$ & $0.3 \pm 0.3$ & $0.3 \pm 0.1$ & $0.4 \pm 0.2$ & $0.6 \pm 0.3$ & $0.5 \pm 0.3$ & $0.4 \pm 0.3$ \\
\hline UQ1102C & 6 & $460 \pm 60$ & $28 \pm 2$ & $1190 \pm 50$ & $130 \pm 10$ & $0.4 \pm 0.2$ & $0.4 \pm 0.1$ & $0.4 \pm 0.1$ & $0.5 \pm 0.2$ & $0.4 \pm 0.1$ & $0.5 \pm 0.2$ \\
\hline UQ0801 & 6 & $840 \pm 110$ & $48 \pm 6$ & $1370 \pm 170$ & $190 \pm 30$ & $0.2 \pm 0.0$ & $0.4 \pm 0.2$ & $0.8 \pm 0.2$ & $1.2 \pm 0.3$ & $0.8 \pm 0.2$ & $0.7 \pm 0.3$ \\
\hline \multicolumn{12}{|c|}{ Echinoderm } \\
\hline UQ1001 & 2 & $160 \pm 20$ & $23 \pm 13$ & $920 \pm 220$ & $110 \pm 30$ & $0.7 \pm 0.0$ & $0.5 \pm 0.3$ & $0.4 \pm 0.0$ & $1.0 \pm 0.1$ & $0.3 \pm 0.1$ & $0.5 \pm 0.1$ \\
\hline UQ0101A & 6 & $220 \pm 60$ & $28 \pm 6$ & $1420 \pm 120$ & $200 \pm 20$ & $24 \pm 37$ & $0.8 \pm 0.6$ & $0.6 \pm 0.2$ & $0.6 \pm 0.2$ & $0.5 \pm 0.1$ & $0.3 \pm 0.1$ \\
\hline UQ1102C & 4 & $200 \pm 80$ & $24 \pm 15$ & $1300 \pm 50$ & $170 \pm 20$ & $0.8 \pm 0.4$ & $0.7 \pm 0.3$ & $0.6 \pm 0.2$ & $0.9 \pm 0.3$ & $0.5 \pm 0.1$ & $0.4 \pm 0.4$ \\
\hline UQ0801 & 4 & $240 \pm 190$ & $47 \pm 13$ & $1340 \pm 120$ & $230 \pm 30$ & $0.4 \pm 0.2$ & $0.6 \pm 0.3$ & $1.4 \pm 1.2$ & $2.3 \pm 1.9$ & $1.1 \pm 0.8$ & $0.5 \pm 0.3$ \\
\hline
\end{tabular}

amount of impurities and coincides with the smallest number of echinoderms.

\section{Discussion}

\subsection{Relationship Among CPO, Chemical Composition, and AMS}

[14] The susceptibility and AMS together with the texture and chemical data, presented in section 3, can be explained by looking among their relationships. From this viewpoint we seek to explain the results as a consequence of (1) the influence of $\mathrm{Fe}^{2+}$ and $\mathrm{Mn}^{2+}$ on bulk susceptibility, which provides a connection between the chemical data and the bulk susceptibility; (2) the influence of $\mathrm{Fe}^{2+}$ on the magnetic anisotropy, which, together with the magnetic anisotropy that is due to the diamagnetic calcite explains the $\mathrm{V}$ shape identified in the data; and (3) the influence of the CPO, which determines the steepness or angle of the "V." These three arguments are elaborated below.

[15] In the calcite crystal lattice, the calcium cation is commonly substituted by elements that fit its position in the molecule. With this respect, most prominent in carbonate rocks is the temperaturedependent solid solution exchange between $\mathrm{Ca}^{2+}$ and $\mathrm{Mg}^{2+}$ [e.g., Goldsmith and Newton, 1969; Anovitz and Essene, 1987]. The most important elements with respect to the magnetic susceptibility, however, are $\mathrm{Fe}^{2+}$ and $\mathrm{Mn}^{2+}$, whereas $\mathrm{Mg}^{2+}$ has only a very limited effect on the magnetic susceptibility. In contrast to $\mathrm{Mn}^{2+}$, divalent iron cations have positive paramagnetic spin moments that align preferentially along the crystallographic $c$ axis. Divalent manganese has a larger susceptibility than iron, but is considerably less anisotropic, as shown by a comparison of the magnetic anisotropy for single crystals of the Mn-carbonate rhodochro- site and Fe-carbonate siderite [Krishnan and Banerjee, 1938; Schmidt et al., 2007b]. In addition the $\mathrm{k}_{1}$ axis of the manganese susceptibility ellipsoid is preferentially oriented parallel to the basal

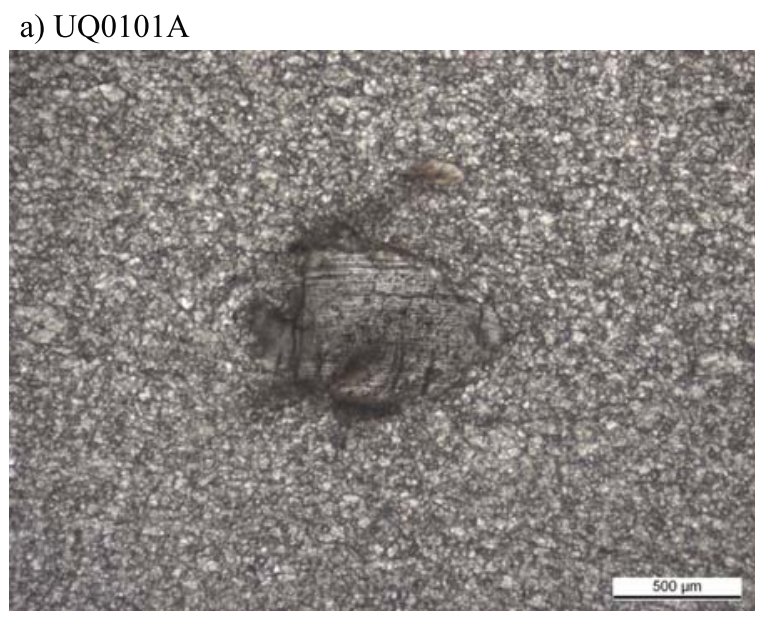

b) UQ0801A

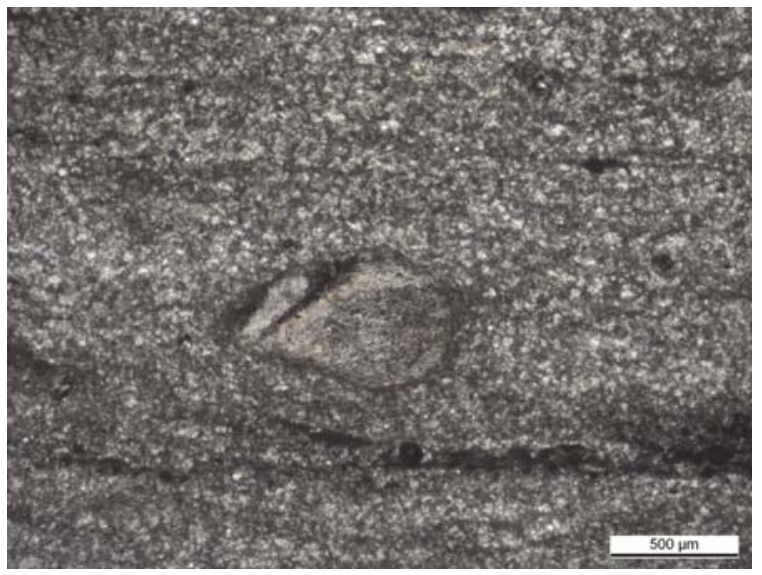

Figure 5. Thin section image in plane-polarized light of echinoderm fragments, embedded in the fine-grained recrystallized calcite matrix of specimens (a) UQ0101A and (b) UQ0801A. 
Bulk susceptibility (SI)

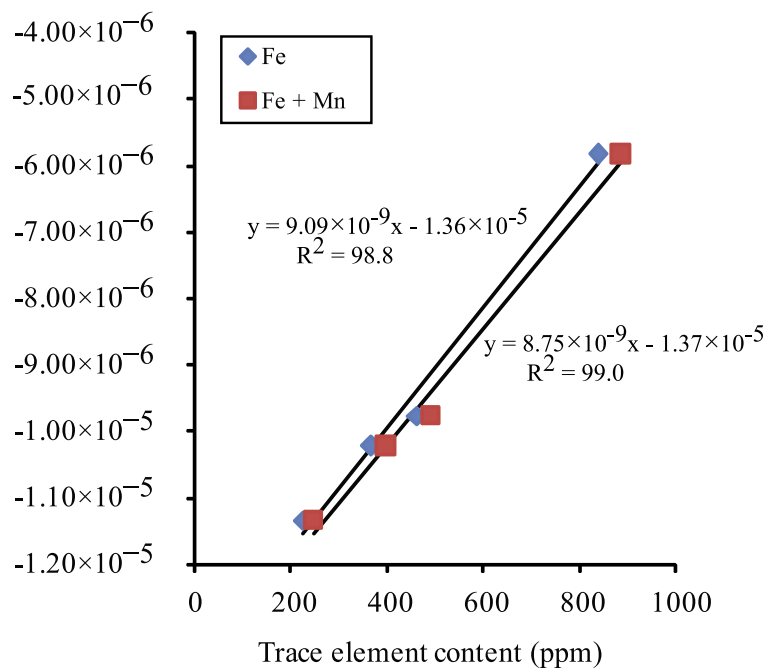

Figure 6. The bulk magnetic susceptibility as a function of $\mathrm{Fe}+\mathrm{Mn}$ trace element content (ppm), measured for the calcite mylonite matrix.

plane of the crystal lattice, rather than parallel to the $c$ axis as for iron [Schmidt et al., 2007b].

[16] The anisotropy of a carbonate crystal or carbonate rock will depend on the amount of paramagnetic cations substituting for calcium, whereby a greater anisotropy is expected as the amount of paramagnetic cations increases. Schmidt et al. [2006] determined an empirical relationship for the paramagnetic susceptibility difference, i.e., the absolute difference between maximum $\left(\mathrm{k}_{1}\right)$ and minimum susceptibility $\left(\mathrm{k}_{3}\right)$ axes $\left(\Delta \mathrm{k}=\left|\mathrm{k}_{1}-\mathrm{k}_{3}\right|\right)$, based on the iron concentration in calcite single crystals, in which

$\Delta \mathrm{k}_{\text {para }}=\mathrm{Fe}$ content $(\mathrm{ppm}) \times(1 \pm 0.1) \times 10^{-12}\left(\mathrm{~m}^{3} / \mathrm{kg} / \mathrm{ppm}\right)$.

This relationship holds for amounts of iron in the range 500-10,000 ppm [Schmidt et al., 2006]. Iron-rich calcite has an inverse magnetic fabric [Jacobs, 1963; Rochette, 1988], where the $\mathrm{k}_{1}$ axis coincides with the $c$ axis of the calcite's crystal lattice. The calcite mylonites display $\mathrm{CPO}$ with $c$ axes clustered perpendicular to the foliation and $a$ axes distributed around a great circle subparallel to the main foliation. This is common in calcite mylonites deformed under greenschist facies [e.g., Bestmann et al., 2000; Ebert et al., 2007]. In terms of magnetic anisotropy, the inverse magnetic fabric due to iron in the carbonate crystal lattice will therefore add linearly and oppositely to the magnetic anisotropy of a pure calcium carbonate. A pure calcium carbonate, composed of an aggregate of calcite crystals, as defined in the introduction, is diamagnetic (i.e., its induced magnetization arises from the electrons orbiting the nucleus) and has an oblate shape magnetic ellipsoid with its maximum susceptibility in the plane containing the crystallographic $a$ axes, and the minimum susceptibility is parallel to the $c$ axis. In a geological sample of pure calcite, the minimum susceptibility is usually perpendicular to the foliation with the maximum susceptibility in the foliation plane. A mixture of a normal magnetic fabric, arising from the diamagnetic calcite, and an inverse magnetic fabric from iron-rich calcite produces an intermediate magnetic fabric, which cannot be simply related to strain [Rochette et al., 1999; Ferré, 2002]. The continuous addition of Fe gradually reduces the anisotropy of the diamagnetic calcite, until the anisotropy becomes dominated by the paramagnetic Fe substitution. Schmidt et al. [2006] have shown that the transition from diamagnetic to paramagnetic dominated anisotropy occurs at an average Fe concentration of $400 \mathrm{ppm}$ at room temperature, based on a suite of calcite single crystals with varying trace concentrations of $\mathrm{Fe}^{2+}$. At $77 \mathrm{~K}$ the transition occurs at substantially lower iron concentrations (150 ppm according to Schmidt et al. [2007b]) as a consequence of increased interaction among the paramagnetic $\mathrm{Fe}^{2+}$. A switch from diamagnetic-dominated to paramagnetic-dominated anisotropy is supported by the inversion of the principal axes, shown in Figure 3 (also seen in the change of shape of the susceptibility ellipsoid in Table 1). Samples with an Fe content higher than $400 \mathrm{ppm}$ have their $\mathrm{k}_{1}$ axis oriented normal to the foliation, whereas samples with less than $400 \mathrm{ppm} F e$ have the $\mathrm{k}_{3}$ axis oriented normal to the foliation plane. At $77 \mathrm{~K}$ the transition to a paramagnetic dominated anisotropy occurs at lower Fe concentrations, which is apparent by the AMS orientations in Figure 3 with $\mathrm{k}_{1}$ oriented normal to the foliation for all samples. The increase in bulk susceptibility as a function of addition of $\mathrm{Fe}$ (and $\mathrm{Mn}$ ) is linear as demonstrated by Figure 6, both for the matrix and the echinoderm fragments. The contribution of manganese to the slope of the linear fit is minor for the matrix. From Figure 6 it is also possible to see that the regression lines have intercepts with the $y$ axis (i.e., no $\mathrm{Fe}$ or $\mathrm{Mn}$ impurities) that are close to the bulk susceptibility of pure calcite.

[17] Owens and Rutter [1978] demonstrated that pure calcites that were deformed experimentally 
a)

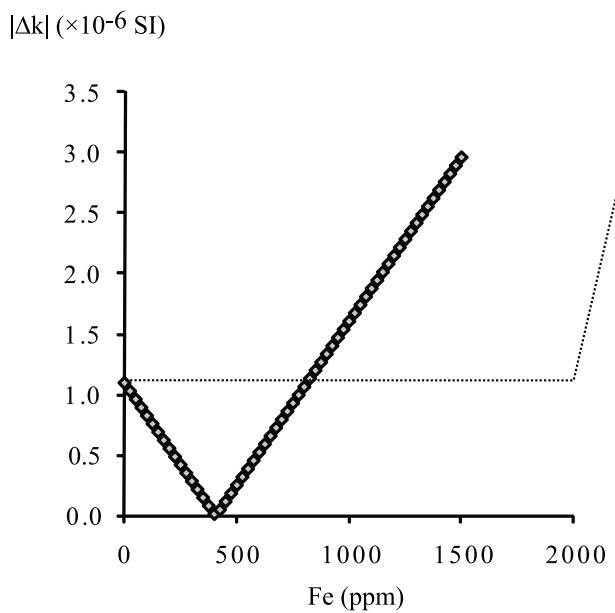

b)

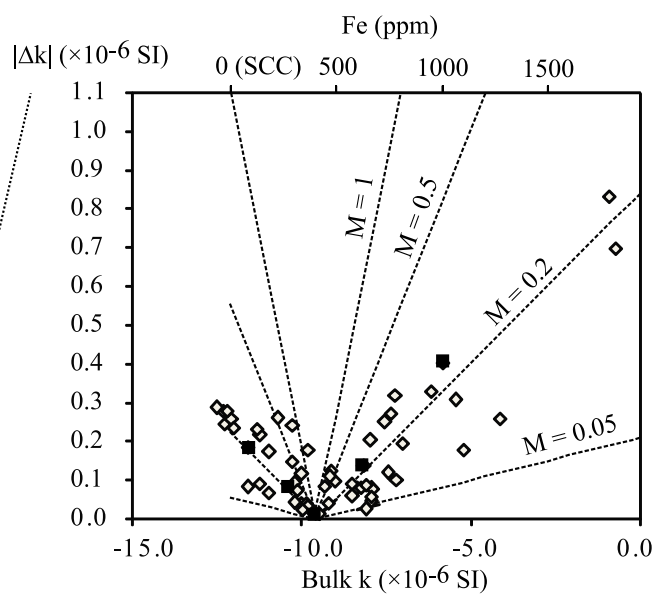

Figure 7. (a) Susceptibility difference for a single crystal of calcite as a function of $\mathrm{Fe}^{2+}$ content and (b) susceptibility difference as a function of $\mathrm{Fe}^{2+}$ content in a sample with different $M$ indices. Diamond symbols in Figure $7 \mathrm{~b}$ correspond to high-field AMS data from locations LQ and UQ, which were measured at room temperature; samples that were investigated with EBSD and LA-ICP-MS are indicated with solid squares. The dashed line shown in Figure 7a relates the scale of the $y$ axis of Figure $7 \mathrm{~b}$.

showed a linear correlation between the optically determined $\mathrm{CPO}$ and $\Delta \mathrm{k}$. It is evident from Figure 2 that the variation in AMS is related to combined effects of the CPO and paramagnetic impurity content. For instance, specimens in Figures $4 b-$ $4 \mathrm{~d}$ have similar texture strength, but their $\Delta \mathrm{k}$ varies significantly. At $77 \mathrm{~K}, \Delta \mathrm{k}$ of the calcite mylonites increases greatly, in some cases by a factor greater than 300 (Figure 2c), when compared with HFAMS at room temperature.

[18] $\Delta \mathrm{k}$ as a function of texture strength has been demonstrated to be linear in synthetic aggregates of calcite and muscovite mixtures [Schmidt et al., 2009]. If we consider a single crystal of calcite with $\Delta \mathrm{k}=1.10 \times 10^{-6}$ SI [Schmidt et al., 2006], and add paramagnetic $\mathrm{Fe}^{2+}$ cations according to the relationship described in equation (1), the mixture of paramagnetic and diamagnetic $\Delta \mathrm{k}$ will display a $\mathrm{V}$-shaped data set with varying amount of $\mathrm{Fe}^{2+}$ (Figure 7a), due to the opposition of their respective anisotropies. A calcite crystal with $\sim 400 \mathrm{ppm}$ $\mathrm{Fe}^{2+}$ substitution is magnetically nearly isotropic, because $\Delta \mathrm{k}_{\text {para }}$ and $\Delta \mathrm{k}_{\text {dia }}$ have a similar magnitude and, therefore, cancel out each other. A further increase in the $\mathrm{Fe}$ content, beyond $400 \mathrm{ppm}$, produces an AMS that is controlled by $\Delta \mathrm{k}_{\text {para }}$ resulting in an increase in $\Delta \mathrm{k}$. A simple model can be constructed that considers the $\mathrm{CPO}$ and $\mathrm{Fe}$ chemistry in a calcite rock. The texture strength can be represented by a value ranging from unity for the single crystal case or perfect alignment of all crystals, to zero in the case of a random texture. A convenient parameter to represent the texture intensity is the $M$ index [Skemer et al., 2005], which is based on the misorientation angles between crystal lattices. The relationship between texture strength, Fe content (represented by $\Delta \mathrm{k}_{\text {para }}$ ) and resulting $\Delta \mathrm{k}$ can be defined as

$$
\Delta \mathrm{k}=\left|\Delta \mathrm{k}_{\text {para }}-\Delta \mathrm{k}_{\text {dia }}\right| \times M,
$$

where $\Delta \mathrm{k}_{\text {para }}$ is described by equation (1), $\Delta \mathrm{k}_{\mathrm{dia}}$ is a constant, the value of which depends on the inherent diamagnetic anisotropy of the crystal in question (in our case calcite), and the $M$ index is a measure of $\mathrm{CPO}$ strength, ranging from zero (random texture) to one (single crystal). The AMS in this case arises only from the preferred orientation of calcite and the amount of iron substitution in the calcite crystal lattice (Figure 7b), where $\Delta \mathrm{k}$ varies according to the specified $M$ and the amount of $\mathrm{Fe}^{2+}$ substitution. HF-AMS data, plotted together with the calculated boundaries for different values of $M$ in Figure $7 \mathrm{~b}$, generally fall between $0.05<M<0.5$, but display some scatter. Texture strength and Fe content are not independent, since $\mathrm{Fe}^{2+}$ has been shown to preferentially align its easy axis magnetic moment parallel to the crystal $c$ axis in the carbonate crystal lattice [Jacobs, 1963]. Therefore it is expected that $\Delta \mathrm{k}$ is larger for a strong CPO as compared with a weak $\mathrm{CPO}$, even though the Fe content is the same in both cases. A preliminary indicator for this is 


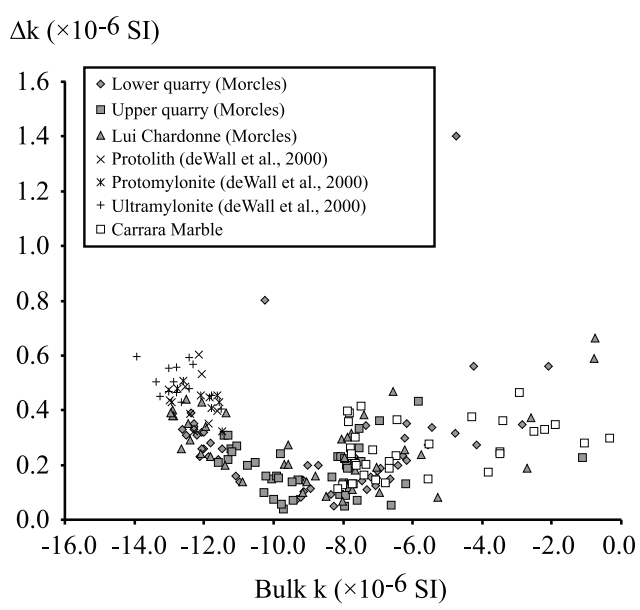

Figure 8. The susceptibility difference $(\Delta \mathrm{k})$ is shown against bulk susceptibility for calcites from three different locations: the Morcles Nappe calcite mylonite, Thassos calcite mylonite, and Carrara marble.

shown by the data obtained from AMS measurements at $77 \mathrm{~K}$ (Figure 2c); different sample groups (with respect to their location along the shear zone) display similar range in bulk susceptibility, but their $\Delta \mathrm{k}$ vary noticeably. This effect is also qualitatively observed in the results of room temperature HF-AMS (Figure 2b), where samples from the distal portion of the shear zone (Dent) have lower $\Delta \mathrm{k}$ values, corresponding to more weakly deformed calcites, whereas samples from the root zone (Martigny) have larger $\Delta \mathrm{k}$, indicating stronger deformation in this area (i.e., stronger $\mathrm{CPO}$ ).

[19] The results of LF and HF-AMS data shown in Figure 2, which display two points of minimum $\Delta \mathrm{k}$ with different bulk susceptibility, cannot be explained solely by equation (2). The shift in bulk susceptibility is due to another paramagnetic cation such as $\mathrm{Mn}^{2+}$, or another paramagnetic or ferromagnetic (in a broad sense) phase (albeit of minor concentration). In the case of Mn, its presence will increase the bulk susceptibility without a considerable affect on the magnetic anisotropy, and this effect could be incorporated in equation (2).

\subsection{AMS of Other Calcite Lithologies}

[20] Other diamagnetic calcites, such as the Thassos mylonites described by de Wall et al. [2000], and Carrara marble, fit well with the data displayed by diamagnetic calcite mylonites from the Morcles Nappe (Figure 8). In the data set of de Wall et al. [2000], $\Delta \mathrm{k}$ values plot to the left in the diagram, above the other data sets and their bulk suscepti- bilities are generally more negative, regardless of which deformation state they are in. Their negative bulk susceptibilities suggest that the samples are made up of chemically pure calcite. AMS data from the Carrara marble show a wider range for $\Delta \mathrm{k}$ and bulk susceptibility, but are still consistent with data from the Morcles Nappe shear zone and Thassos; their $\mathrm{k}$ values are generally lower than specimens from the other sites, suggesting that their CPOs are weaker. Although samples from the Morcles Nappe and Thassos have been intensely deformed, their $\Delta \mathrm{k}$ values are not in the vicinity of the $\Delta \mathrm{k}$ for a single crystal of calcite $(\Delta \mathrm{k}=1.10 \times$ $10^{-6} \mathrm{SI}$ ). This is to be expected since the $\mathrm{M}$ index for specimens from the Gray Urgonian has values $<1$ (Table 1). The trend displayed by the data sets in Figure 8 does however provide insight on the interplay between chemical composition and texture development of calcites, as reflected by AMS studies. The AMS of the carbonate samples, in particular $\Delta \mathrm{k}$, can be satisfactorily explained by the quantity of paramagnetic cations in their crystal lattice and their $\mathrm{CPO}$ intensity.

\subsection{Role of Impurities on Deformation of Calcite Mylonites}

[21] It is well established that small amounts of impurities affect the grain growth mechanisms and deformation processes in calcite rocks [e.g., Walker et al., 1990; Wang et al., 1996; Covey-Crump, 1997; Freund et al., 2001, 2004; Herwegh et al., 2003; Xu et al., 2009]. Freund et al. [2001, 2004] studied the growth and deformation of calcite doped with $\mathrm{Mn}$ as a trace element (ranging from 10 to $670 \mathrm{ppm}$ ), and observed a significant increase in both grain growth and the rate of creep when the Mn concentration increased. Conversely, Xu et al. [2009] and Herwegh et al. [2003] observed that the incorporation of dissolved $\mathrm{Mg}$ led to a retardation of the creep rate during experimental deformation experiments. However, the $\mathrm{Mg}$ concentrations were significantly higher (up to $0.34 \mathrm{~mol} \% \mathrm{MgCO}_{3}$ ) in their experiments.

[22] In the present work we have observed differences with respect to chemical composition in specimens from the same lithological unit. The differences are most marked for the elements $\mathrm{Fe}$, $\mathrm{Mn}, \mathrm{Mg}$ and $\mathrm{Sr}$. In particular, the differences in Fe and $\mathrm{Mn}$ influence the magnetic susceptibility and its anisotropy. There is a noticeable absence of reports in the literature about the effect of $\mathrm{Fe}$ on grain growth and deformation of calcite. However, Fe is likely to have an influence on creep mecha- 
nisms similar to the effect of Mn observed by Freund et al. [2001, 2004] and Wang et al. [1996]. Given that the echinoderm single crystals (1) show no evidence for grain internal crystal plastic deformation and dynamic recrystallization, (2) are in some cases affected by brittle fractures that were healed due to calcite precipitation, and (3) are embedded in a fine-grained calcite matrix, the echinoderm clasts must have higher rock strength than the fine-grained matrix. A possible explanation for such a difference in viscosity is that the grain size difference permits a more pronounced contribution of diffusion processes (diffusion creep) in the matrix calcite, which results in a reduced strength [e.g., Walker et al., 1990; Herwegh et al., 2003]. Additionally, the compositional differences between matrix and echinoderms may also contribute to the variations in rheology (Table 2). Whereas $\mathrm{Mg}$, as dominant minor element, and Mn surprisingly allow no discrimination between echinoderms and matrix, both $\mathrm{Fe}$ and $\mathrm{Sr}$ contents systematically represent lower and higher contents in the echinoderms, respectively (Table 2 ). Without mechanical data, we can only speculate about the rheological implications of these chemical variations at the present stage.

[23] On average, the net amount of chemical impurities ( $\mathrm{Fe}, \mathrm{Mn}, \mathrm{Mg}, \mathrm{Sr}$ ) is higher in the matrix compared to the echinoderms. This suggests that either the effect of chemical impurities has only a subordinate importance on rheology (grain size effect dominates), or that specific elements (e.g., $\mathrm{Fe}, \mathrm{Mn}$ ) have a much more pronounced effect on rheology than others (e.g., Mg). An element-specific influence on rheology can be assumed from experimental rock deformation data. For Mn, an increase in the trace element concentrations from $10 \mathrm{ppm}$ to $670 \mathrm{ppm}$ can already induce a decrease in differential shear stress by a factor of about 1.52 for deformation dominated by dislocation creep under laboratory conditions [see Freund et al., 2004, Figure 5]. A substantial increase in $\mathrm{Mg}$ concentrations from $12,150 \mathrm{ppm}$ to $41,200 \mathrm{ppm}$ induces an increase in stress by a factor of 3 [see $X u$ et al., 2009, Figure 8]. Hence, compared to Mg, small amounts of Mn are more critical in terms of their influences on strength. Since Fe has similar ionic radius and bonding characteristics to $\mathrm{Mn}$, it can be speculated that $\mathrm{Fe}$ may have a similar effect on rock strength. The origin of the differences in trace element chemistry between samples most likely reflects the original sedimentary record, and the higher echinoderm count is found for samples containing larger amounts of trace elements (Table 1).
[24] Whether it is possible to demonstrate an influence of trace element content on the texture development in the calcite mylonites, and indirectly on their strain, remains an open question because other variables, such as the presence of small, albeit significant, amounts of secondary phases have an effect on deformation properties and grain growth in the calcite mylonites. All samples collected display a systematic variation in AMS and bulk susceptibility along the entire shear zone, evident from the $\mathrm{V}$ shape of the collective data, reflecting the amount of impurity elements ( $\mathrm{Fe}$ in particular), but from the current study it is not possible to confirm the role of trace elements due to the limited number of samples analyzed for the purpose of studying the microfabric development. The variation in trace element content, as inferred from the AMS, is potentially important for the rheology of the shear zone itself. It is clear however that AMS and bulk susceptibility provide a proxy for the concentration of impurity elements ( $\mathrm{Fe}$ and $\mathrm{Mn}$ ) in the studied calcite mylonites, and probably in other carbonate settings where the secondary phase content is small. In such geological settings it seems likely that local variations in trace element concentrations (e.g., $\mathrm{Mg}, \mathrm{Sr}, \mathrm{Fe}, \mathrm{Mn}$ ) will help dictate rheological behavior and strain weakening [Wang et al., 1996; Bestmann et al., 2000; Freund et al., 2001, 2004].

[25] Finally, with regards to the results shown in Figure 8, we suggest that measurements of magnetic susceptibility and AMS can be used for applications relating to $\mathrm{Mg}$ and $\mathrm{Fe}$ temperaturedependent solid solution exchange of $\mathrm{Ca}$ in carbonates. Information on solid solutions in carbonates are of great interest in terms of (1) geothermometry and (2) the effect on solute impurities on the carbonate rheology. Carbonate chemistry with respect to $\mathrm{Mg}, \mathrm{Fe}$ and $\mathrm{Ca}$ has been shown to be temperature-dependent, which has for example given rise to the use of carbonate thermometry [Rosenberg, 1963, 1967; Goldsmith and Newton, 1969; Barron, 1974; Anovitz and Essene, 1987]. Given that there is enough $\mathrm{Fe}$ available in the carbonate rock, the exchange of $\mathrm{Ca}$ follows a temperature-dependent solid solution that could be recognized in the magnetic susceptibility and AMS. As documented by recent experimental studies [Herwegh et al., 2003; Freund et al., 2004; $X u$ et al., 2009], solute impurities can affect the rheology of calcite substantially. Time-consuming microstructural analyses would have to be carried out on large sample series collected across shear zones, to obtain spatially resolved information in 
the microstructural evolution of shear zones [e.g., Bestmann et al., 2000; Ebert et al., 2007; Austin et al., 2008; Herwegh et al., 2008]. The associated strain localization might be affected, for example, by changes in deformation mechanisms [e.g., Burlini and Bruhn, 2005, and references therein], which can be recognized by changes in CPO intensity and by variations in trace element content. Since the presence of $\mathrm{Mn}$ and $\mathrm{Fe}$ in combination with the CPO affects the magnetic susceptibility, AMS could be used to rapidly screen rock samples for changes in magnetic susceptibility related to trace element variations, allowing for the selection of samples for detailed quantitative microstructural and chemical analyses on impure samples versus pure samples. It may be of interest in forthcoming AMS studies to consider calcites, dolomites and $\mathrm{Fe}$-carbonates deformed at a wider range of metamorphic grades and chemical compositions.

\section{Conclusions}

[26] In this study two properties dominantly control the AMS measured in calcite mylonites with varying impurity content $(<10$ vol $\%$ second phases). The first property is chemical composition, specifically the amount and type of substituted paramagnetic cations in the calcite crystal lattice. As the amount of paramagnetic cations increases, the paramagnetic anisotropy increases. $\mathrm{Fe}^{2+}$ in particular contributes to the paramagnetic anisotropy, and is more anisotropic than other observed cations that substitute for $\mathrm{Ca}^{2+}$ in the carbonate crystal lattice. The second property that gives rise to the AMS is the sample texture. A weakly deformed, or isotropic, calcite displays low $\Delta \mathrm{k}$ due to a weak CPO, whereas increasing deformation produces susceptibility differences, due to the development of a stronger CPO, which will approach the AMS for single crystal calcite [Owens and Rutter, 1978]. AMS results obtained at $77 \mathrm{~K}$ and modeling results suggest that the two properties controlling the AMS, of chemical and physical origin, are coupled. Small deviations from the general trend observed in the data sets reflect the presence of small amounts of other paramagnetic or ferromagnetic (in a broad sense) phases, but these do not greatly alter the general trend of the data.

[27] The amount of trace elements $\mathrm{Fe}, \mathrm{Mn}, \mathrm{Mg}$ and Sr covary systematically within each specimen that was investigated. Experimental deformation studies [e.g., Freund et al., 2001, 2004; Herwegh et al., 2003] have previously shown that variable trace element concentration (ppm) in calcites have a large effect on deformation properties and grain growth, and could lead to the localization of deformation and strain in layers with particular trace impurity composition. As such, magnetic susceptibility provides a suitable tool for studying the variation of impurities in calcite rocks, for example in a screening process with an initial large sample set, which enables more detailed microfabric studies on selected samples.

\section{Acknowledgments}

[28] The work was supported by the Swiss National Science Foundation, project 2-77070-07. We thank two anonymous reviewers, the Associate Editor, and William Lowrie for their comments and suggestions, which improved the manuscript. Frovin Pirovino prepared the thin sections that were used for texture and chemical analysis. The plots shown in Figure 4 were produced using software written by David Mainprice.

\section{References}

Almqvist, B. S. G., A. M. Hirt, V. Schmidt, and D. Dietrich (2009), Magnetic fabrics of the Morcles Nappe complex, Tectonophysics, 466, 89-100, doi:10.1016/j.tecto.2008 .07.014

Anovitz, L. M., and E. J. Essene (1987), Phase equilibria in the system $\mathrm{CaCO}_{3}-\mathrm{MgCO}_{3}-\mathrm{FeCO}_{3}$, J. Petrol., 28, 389-414.

Austin, N., B. Evans, M. Herwegh, and A. Ebert (2008), Strain localization in the Morcles nappe (Helvetic Alps, Switzerland), Swiss J. Geosci., 101, 341-360, doi:10.1007/s00015-0081264-2.

Barron, B. J. (1974), The use of coexisting calcite-ankerite solid solutions as a geothermometer, Contrib. Mineral. Petrol., 47, 77-80, doi:10.1007/BF00418558.

Bergmüller, F., C. Bärlocher, B. Geyer, M. Grieder, F. Heller, and P. Zweifel (1994), Torque magnetometer for measurements of the high-field anisotropy of rocks and crystals, Meas. Sci. Technol., 5, 1466-1470, doi:10.1088/09570233/5/12/007.

Bestmann, M., K. Kunze, and A. Matthews (2000), Evolution of a calcite marble shear zone complex on Thassos Island, Greece: Microstructural and textural fabrics and their kinematic significance, J. Struct. Geol., 22, 1789-1807, doi:10.1016/S0191-8141(00)00112-7.

Borradaile, G. J., and B. Henry (1997), Tectonic applications of magnetic susceptibility and its anisotropy, Earth Sci. Rev., 42, 49-93, doi:10.1016/S0012-8252(96)00044-X.

Bunge, H.-J. (1982), Texture Analysis in Materials Science, 593 pp., Butterworth, Berlin.

Burlini, L., and D. Bruhn (2005), High-strain zones: Laboratory perspectives on strain softening during ductile deformation, Geol. Soc. Spec. Publ., 245, 1-24, doi:10.1144/ GSL.SP.2005.245.01.01.

Covey-Crump, S. J. (1997), The normal grain growth behavior of nominally pure calcitic aggregates, Contrib. Mineral. Petrol., 129, 239-254, doi:10.1007/s004100050335.

de Wall, H., and H.-U. Worm (1993), Field dependence of magnetic anisotropy in pyrrhotite: Effects of texture and grain shape, Phys. Earth Planet. Inter., 76, 137-149, doi:10.1016/0031-9201(93)90063-F. 
de Wall, H., M. Bestmann, and K. Ullemeyer (2000), Anisotropy of diamagnetic susceptibility in Thassos marble: A comparison between measured and modeled data, J. Struct. Geol., 22, 1761-1771, doi:10.1016/S0191-8141 (00)00105-X.

Dietrich, D. (1989), Fold-axis parallel extension in an arcuate fold- and thrust belt: The case of the Helvetic nappes, Tectonophysics, 170, 183-212, doi:10.1016/0040-1951(89) 90271-0.

Dietrich, D., and H. Song (1984), Calcite fabrics in a natural shear environment, the Helvetic nappes of western Switzerland, J. Struct. Geol., 6, 19-32, doi:10.1016/01918141(84)90080-4.

Durney, D. W. (1972), Deformation history of the western Helvetic nappes, Valais, Switzerland, Ph.D. thesis, Imperial Coll., London.

Ebert, A., M. Herwegh, B. Evans, A. O. Pfiffner, N. Austin, and T. Venneman (2007), Microfabrics in carbonate mylonites along a large-scale shear zone (Helvetic nappes), Tectonophysics, 444, 1-26, doi:10.1016/j.tecto.2007.07.004.

Escher, A., H. Masson, and A. Steck (1993), Nappe geometry in the western Swiss Alps, J. Struct. Geol., 15, 501-509, doi:10.1016/0191-8141(93)90144-Y.

Ferré, E. C. (2002), Theoretical models of intermediate and inverse AMS fabrics, Geophys. Res. Lett., 29(7), 1127, doi:10.1029/2001GL014367.

Föllmi, K. B., and F. Gainon (2008), Demise of the northern Tethyan Urgonian carbonate platform and subsequent transition towards pelagic conditions: The sedimentary record of the Col de la Plaine Morte area, central Switzerland, Sediment. Geol., 205, 142-159, doi:10.1016/j.sedgeo. 2008.02.005.

Freund, D., E. Rybacki, and G. Dresen (2001), Effects of impurities on grain growth in synthetic calcite aggregates, Phys. Chem. Miner., 28, 737-745, doi:10.1007/ s002690100196.

Freund, D., Z. Wang, E. Rybacki, and G. Dresen (2004), High temperature creep of synthetic calcite aggregates: Influence of Mn content, Earth Planet. Sci. Lett., 226, 433-448, doi:10.1016/j.epsl.2004.06.020.

Frey, M., M. Teichmueller, R. Teichmueller, J. Mullis, B. Kuenzi, A. Breitschmid, U. Gruner, and B. Schwizer (1980), Very low-grade metamorphism in external parts of the Central Alps; illite crystallinity, coal rank and fluid inclusion data, Eclogae Geol. Helv., 73, 173-203.

Goldsmith, J. R., and R. C. Newton (1969), P-T-X relations in the system $\mathrm{CaCO}_{3}-\mathrm{MgCO}_{3}$ at high temperatures and pressures, Am. J. Sci., 267A, 160-190.

Graham, J. W. (1954), Magnetic susceptibility anisotropy, an unexploited petrofabric element, Geol. Soc. Am. Bull., 65, $1257-1258$.

Graham, J. W. (1966), Significance of magnetic anisotropy in Appalachian sedimentary rocks, in The Earth Beneath the Continents, Geophys. Monogr. Ser., vol. 10, edited by J. S. Steinhart and T. J. Smith, pp. 627-648, AGU, Washington, D. C.

Hatcher, R. D.,Jr. (1995), Structural Geology: Principles, Concepts, and Problems, Prentice Hall, Englewood Cliffs, N. J.

Heitzmann, P. (1987), Calcite mylonites in the Central Alpine "root zone,", Tectonophysics, 135, 207-215, doi:10.1016/ 0040-1951(87)90162-4.

Herwegh, M., and A. Berger (2004), Deformation mechanisms in second-phase affected microstructures and their energy balance, J. Struct. Geol., 26, 1483-1498, doi:10.1016/ j.jsg.2003.10.006.
Herwegh, M., and K. Kunze (2002), The influence of nanoscale second-phase particles on deformation of fine grained calcite mylonites, J. Struct. Geol., 24, 1463-1478, doi:10.1016/S0191-8141(01)00144-4.

Herwegh, M., X. Xiao, and B. Evans (2003), The effect of dissolved magnesium on diffusion creep in calcite, Earth Planet. Sci. Lett., 212, 457-470, doi:10.1016/S0012821X(03)00284-X.

Herwegh, M., A. Berger, and A. Ebert (2005), Grain coarsening maps: A new tool to predict microfabric evolution of polymineralic rocks, Geology, 33, 801-804, doi:10.1130/ G21789.1.

Herwegh, M., A. Berger, A. Ebert, and S. Brodhag (2008), Discrimination of annealed and dynamic fabrics: Consequences for strain localization and deformation episodes of large-scale shear zones, Earth Planet. Sci. Lett., 276, 52-61, doi:10.1016/j.epsl.2008.09.007.

Hrouda, F. (1982), Magnetic anisotropy of rocks and its application in geology and geophysics, Geophys. Surv., 5, 37-82, doi:10.1007/BF01450244.

Hrouda, F. (2002), Low-field variation of magnetic susceptibility and its effect on the anisotropy of magnetic susceptibility or rocks, Geophys. J. Int., 150, 715-723, doi:10.1046/j.1365-246X.2002.01731.x.

Hrouda, F. (2004), Problems in interpreting AMS parameters in diamagnetic rocks, in Magnetic Fabric: Methods and Applications, edited by F. Martin-Hernandez et al., Geol. Soc. Spec. Publ., 238, 49-59.

Ihmlé, P. F., A. M. Hirt, W. Lowrie, and D. Dietrich (1989), Inverse magnetic fabric in deformed limestones of the Morcles Nappe, Switzerland, Geophys. Res. Lett., 16(12), 1383-1386, doi:10.1029/GL016i012p01383.

Ising, G. (1942), On the magnetic properties of varved clay, Ark. Mat. Astron. Fys., 29A, 1-37.

Jackson, M. J., and L. Tauxe (1991), Anisotropy of magnetic susceptibility and remanence: Developments in the characterization of tectonic, sedimentary, and igneous fabric, Rev. Geophys., 29, suppl., 371-376.

Jackson, M., B. Moskowitz, J. Rosenbaum, and C. Kissel (1998), Field-dependence of AC susceptibility in titanomagnetites, Earth Planet. Sci. Lett., 157, 129-139, doi:10.1016/ S0012-821X(98)00032-6.

Jackson, S. (2008), LAMTRACE data reduction software for LA-ICP-MS, in Laser Ablation ICP-MS in the Earth Sciences: Current Practices and Outstanding Issues, edited by P. Sylvester, Mineral. Assoc. Can. Short Course Ser., 40, 305-307.

Jacobs, I. S. (1963), Metamagnetism of siderite $\left(\mathrm{FeCO}_{3}\right)$, J. Appl. Phys., 34, 1106-1107, doi:10.1063/1.1729389.

Jelinek, V. (1981), Characterization of the magnetic fabric of rocks, Tectonophysics, 79, T63-T67, doi:10.1016/00401951(81)90110-4.

Kennedy, L. A., and J. M. Logan (1998), Microstructures of cataclasites in a limestone-on-shale thrust fault: Implications for low-temperature recrystallization of calcite, Tectonophysics, 295, 167-186, doi:10.1016/S0040-1951(98)00119-X.

Kennedy, L. A., and J. C. White (2001), Low-temperature recrystallization in calcite: Mechanisms and consequences, Geology, 29, 1027-1030, doi:10.1130/0091-7613(2001) 029<1027:LTRICM>2.0.CO;2.

Kligfield, R., W. Lowrie, and I. W. D. Dalziel (1977), Magnetic susceptibility anisotropy as a strain indicator in Sudbury basin, Ontario, Tectonophysics, 40, 287-308, doi:10.1016/ 0040-1951(77)90070-1. 
Krishnan, K. S., and S. Banerjee (1938), Magnetic studies on rhodochrosite, $\mathrm{MnCO}_{3}$, Z. Kristallogr. Mineral. Petrogr., 99, 499-508.

Martín-Hernández, F., and E. C. Ferré (2007), Separation of paramagnetic and ferrimagnetic anisotropies: A review, J. Geophys. Res., 112, B03105, doi:10.1029/2006JB004340.

McCabe, C., M. Jackson, and B. B. Ellwood (1985), Magnetic anisotropy in the Trenton limestone: Results of a new technique, anisotropy of anhysteretic susceptibility, Geophys. Res. Lett., 12, 333-336, doi:10.1029/GL012i006p00333.

Nagata, T. (1961), Rock Magnetism, 352 pp., Maruzen, Tokyo.

Olgaard, D., and B. Evans (1986), Effect of second-phase particles on grain growth in calcite, J. Am. Ceram. Soc., 69, C272-C277, doi:10.1111/j.1151-2916.1986.tb07374.x.

Olgaard, D., and B. Evans (1988), Grain growth in synthetic marbles with added mica water, Contrib. Mineral. Petrol., 100, 246-260, doi:10.1007/BF00373591.

Owens, W. H. (1974), Mathematical model studies on factors affecting the magnetic anisotropy of deformed rocks, Tectonophysics, 24, 115-131, doi:10.1016/0040-1951(74)90133-4.

Owens, W. H., and E. H. Rutter (1978), The development of magnetic susceptibility anisotropy through crystallographic preferred orientation in a calcite rock, Phys. Earth Planet. Inter, 16, 215-222, doi:10.1016/0031-9201(78)90014-6.

Pettke, T. (2008), Analytical protocols for element concentration and isotrope ration measurements in fluid inclusions by LA-(MC)-ICP-MS, in Laser Ablation ICP-MS in the Earth Sciences: Current Practices and Outstanding Issues, edited by P. Sylvester, Mineral. Assoc. Can. Short Course Ser., 40, $189-218$.

Potter, D. K., and A. Stephenson (1988), Single domain particles in rocks and magnetic fabric analysis, Geophys. Res. Lett., 15, 1097-1100, doi:10.1029/GL015i010p01097.

Ramsay, J. G. (1981), Tectonics of the Helvetic nappes, in Thrust and Nappe Tectonics, edited by K. R. McClay and N. J. Price, Geol. Soc. Spec. Publ., 9, 293-309.

Rochette, P. (1987), Magnetic susceptibility of the rock matrix related to magnetic fabric studies, J. Struct. Geol., 9, 10151020, doi:10.1016/0191-8141(87)90009-5.

Rochette, P. (1988), Inverse magnetic fabric in carbonate-bearing rocks, Earth Planet. Sci. Lett., 90, 229-237, doi:10.1016/0012-821X(88)90103-3.

Rochette, P., M. Jackson, and C. Aubourg (1992), Rock magnetism and the interpretation of anisotropy of magnetic susceptibility, Rev. Geophys., 30, 209-226, doi:10.1029/ 92RG00733.

Rochette, P., C. Aubourg, and M. Perrin (1999), Is this magnetic fabric normal? A review and case studies in volcanic formations, Tectonophysics, 307, 219-234, doi:10.1016/ S0040-1951(99)00127-4.
Rosenberg, P. E. (1963), Subsolidus relations in the system $\mathrm{CaCO}_{3}-\mathrm{FeCO}_{3}$, Am. J. Sci., 261, 683-690.

Rosenberg, P. E. (1967), Subsolidus relations in the system $\mathrm{CaCO}_{3}-\mathrm{MgCO}_{3}-\mathrm{FeCO}_{3}$ between $350^{\circ} \mathrm{C}$ and $550^{\circ} \mathrm{C}, \mathrm{Am}$. Mineral., 52, 787-796.

Schmidt, V., D. Günther, and A. M. Hirt (2006), Magnetic anisotropy of calcite at room-temperature, Tectonophysics, 418, 63-73, doi:10.1016/j.tecto.2005.12.019.

Schmidt, V., A. M. Hirt, P. Rosselli, and F. Martín-Hernández (2007a), Separation of diamagnetic and paramagnetic anisotropy by high-field, low-temperature torque measurements, Geophys. J. Int., 168, 40-47, doi:10.1111/j.1365246X.2006.03202.x.

Schmidt, V., A. M. Hirt, K. Hametner, and D. Günther (2007b), Magnetic anisotropy of carbonate minerals at room temperature and 77K, Am. Mineral., 92, 1673-1684, doi:10.2138/am.2007.2569.

Schmidt, V., A. M. Hirt, B. Leiss, L. Burlini, and J. M. Walter (2009), Quantitative correlation of texture and magnetic anisotropy of compacted calcite-muscovite aggregates, J. Struct. Geol., 31, 1062-1073, doi:10.1111/J.1365-1246X.2006. 03202.X.02007.

Skemer, P., I. Katayama, Z. Jiang, and S. Karato (2005), The misorientation index: Development of a new method for calculating the strength of lattice-preferred orientation, Tectonophysics, 411, 157-167, doi:10.1016/j.tecto.2005.08.023.

Stacey, F. (1960), Magnetic anisotropy of igneous rocks, J. Geophys. Res., 65, 2429-2442, doi:10.1029/ JZ065i008p02429.

Stampfli, G. M., G. D. Borel, W. Cavazza, J. Mosar, and P. J. Ziegler (2001), Paleotectonic and paleogeographic evolution of the western Tethys and PeriTethyan domain, Episodes, 24, $222-228$.

van der Pluijm, B. A. (1991), Marble mylonities in the Bancroft shear zone, Ontario, Canada: Microstructures and deformation mechanisms, J. Struct. Geol., 13, 1125-1135, doi:10.1016/0191-8141(91)90073-R.

Walker, A. N., E. H. Rutter, and K. H. Brodie (1990), Experimental study of grain-size sensitive flow of synthetic, hotpressed calcite rocks, in Deformation Mechanisms, Rheology and Tectonics, edited by R. J. Knipe and E. H. Rutter, Geol. Soc. Spec. Publ., 54, 259-284.

Wang, Z.-C., Q. Bai, G. Dresen, R. Wirth, and B. Evans (1996), High-temperature deformation of calcite sing crystals, J. Geophys. Res., 101, 20,377-20,390, doi:10.1029/ 96JB01186.

Xu, L., J. Renner, M. Herwegh, and B. Evans (2009), The effect of dissolved magnesium on creep of calcite II: Transition from diffusion creep to dislocation creep, Contrib. Min. Petrol., 157, 339-358, doi:10.1007/s00410-008-0338-5. 